\title{
What is Etiquette Today? Interviewing Etiquette for Today's College Student
}

\author{
Michael J. Tews ${ }^{1}$, Kelly Frager ${ }^{2}$, Ashley I. Citarella ${ }^{3}$ and Robert M. Orndorff ${ }^{3}$ \\ ${ }^{1}$ School of Hospitality Management, Pennsylvania State University, United States \\ ${ }^{2}$ Bluewater Advisory, United States \\ ${ }^{3}$ Career Services, Pennsylvania State University, United States \\ Email: mjt17@psu.edu
}

\begin{abstract}
As societal norms continue to evolve, it is not altogether clear what constitutes proper interviewing etiquette today. With a sample of 290 recruiters across three industry segments (business, education and social services, and science and technology), the present study sought to determine what interviewing etiquette practices recruiters value. Among a pool of 20 items, our findings highlight that recruiters most highly value being on time for the interview, shaking hands properly, and exhibiting a neat and professional appearance. At the same time, there was a fair amount of variability in recruiters' values regarding handwritten thank you notes, the use of slang, and exhibiting tattoos. Furthermore, there were significant differences across the three industry segments.
\end{abstract}

Keywords: Interviewing; job search; etiquette; impression management.

\section{Introduction}

In addition to personal and intellectual growth, securing the best internships and full-time employment are primary goals for the majority of today's college students. In fact, the importance students place on an institution's ability to help them secure good jobs has increased markedly over the past three decades (Eagan, Stolzenberg, Bates, Aragon, Suchard, \& Rios-Aguilar, 2015). Moreover, over sixty percent of students place securing good post-graduation employment as a very important consideration in their college decision-making process, reaching an all-time high in 2015 (Eagan et al., 2015). Despite its importance, securing employment is not necessarily an easy endeavor as most students seek to enter the professional workforce for the first time. Fundamentally, success resides in possessing (or pursuing) a relevant degree, quality experience, and the knowledge, skills, and personality characteristics for the job at hand. At the same time, job search success involves interacting professionally and courteously with recruiters, hiring managers, and potential coworkers throughout the selection process. On this front, adhering to proper interviewing etiquette becomes salient.

Although most individuals would certainly agree that exhibiting proper interviewing etiquette is important for job search success, it is not altogether clear what constitutes proper interviewing etiquette today. To help enhance one's understanding of interviewing etiquette for today's college student, the present study will assess the importance that recruiters in three industry segments (business, education and social services, and science and technology) place on 20 different interviewing etiquette practices. Specifically, the goals of this research are threefold: 1) to determine what etiquette practices matter most among recruiters; 2) to assess variability in recruiters' etiquette values, that is, whether recruiters agree on what is important; and 3) to evaluate the extent to which recruiters in different industry segments differ in the emphasis they place on etiquette.

Determining what constitutes interviewing etiquette today has relevance for academic advising on several related fronts. While the central focus of academic advising is on helping students develop and manage their academic program of study, advisor-student discussions may often involve conversations relating to job search success. As some advisors and students develop higher quality mentor-mentee relationships, students may seek greater levels of advice from advisors, including how best to succeed in interviews for internships and post-graduation employment. A number of books have been written on the topic of interviewing etiquette, including 60 Seconds and You're Hired (Ryan, 2016), Knock 'em 
Dead Job Interview (Yate, 2012), and Modern Manners: Tools to Take You to the Top (Johnson \& Tyler, 2013), to name but a few. Notwithstanding the merit of the suggestions offered in titles such as these, the present study seeks to prioritize the wide variety of interviewing etiquette prescriptions. Ultimately, this study will provide a more nuanced picture of interviewing etiquette and will equip academic advisors with potentially valuable and detailed information to guide students in their job search endeavors.

\subsection{What is Etiquette and Why Should It Matter?}

Formally speaking, etiquette refers to "the customary code of polite behavior in society or among members of a particular profession or group" (Etiquette, n.d.). Etiquette is a collection of often unwritten guidelines and behaviors that defines an individual's ability to successfully navigate a variety of social and professional situations. Perhaps the name that is most synonymous with etiquette is Emily Post. For over 70 years, The Emily Post Institute has advanced the discussion and practice of proper etiquette and manners throughout the U.S. and beyond. The Emily Post Institute aptly asserts that it may be one's resume that wins the interview, but it is one's people skills that win the job (The Emily Post Institute, n.d.). The present study focuses specifically on interviewing etiquette, which we define as the customary code of polite behavior that prospective employees adhere to (or should adhere to) during interactions with recruiters, hiring managers, and other members of an organization during the interview process. Previous research on interviewing etiquette has been limited, and we thus offer the definition above to guide this research.

Beyond demonstrating courtesy to others simply because it may be the right thing to do, exhibiting proper interviewing etiquette likely has instrumental benefits for job candidates. On one front, job candidates demonstrate that they can adhere to professional workplace norms by exhibiting proper interviewing etiquette. Gardner (1992) has argued that candidates are on stage to create favorable impressions throughout the employment interview. When candidates adhere to standard interview practice, they are more apt to be perceived favorably, and recruiters might infer greater maturity, conscientiousness, and intelligence. In addition, exhibiting proper interviewing etiquette is an avenue though which candidates demonstrate person-iob fit, the compatibility between a person's characteristics and the requirements for a job (Kristof-Brown \& Guay, 2011). To the extent that a job involves professional and cooperative interactions with others (e.g., sales, customer service, teamwork, and management positions), adhering to proper interviewing etiquette could signal that candidates will exhibit appropriate behavior once on the job. In a related vein, when candidates adhere to an organization's specific standards of interviewing etiquette, they signal value congruence, a fundamental component of person-orqanization fit (Kristof, 1996). In this respect, candidates are able to demonstrate that they fit with an organization's culture. Despite the presumed importance of interviewing etiquette, not all individuals may be well versed in etiquette or believe that etiquette fundamentally matters in whether they obtain offers of employment.

The existing body of research on interviewing etiquette is relatively small. To date, researchers have addressed topics such as proper cell phone etiquette among college students (Lipscomb, Totten, Cook, \& Lesch, 2007) and tattoos, piercings, and dress code (Mishra \& Mishra, 2015; Swanger, 2006; Timming, 2015). The take-home message from these studies is that job candidates who adhere to proper etiquette will succeed in the job search process, with the caveat that the workplace is becoming more informal and accepting of evolving non-conventional trends (Mishra \& Mishra, 2015). For example, tattoos, informal dress, and cell phone usage may be less of an issue in interviewing etiquette than they once were.

Research on organizational citizenship behavior (OCB) supports the importance of etiquette in general in the workplace. Organ (1988), a pioneer in OCB research, defines OCB as "individual behavior that is discretionary, not directly or explicitly recognized by the formal reward system, and that in the aggregate promotes the effective functioning of the organization" (p. 4). Examples of OCBs that parallel etiquette include courtesy (consulting with others before taking action), altruism (helping others with heavy workloads), and sportsmanship (not complaining about trivial matters) (Organ, 1988). Spanning several decades, a vast body of research has validated the importance of OCB in enhancing organizational well-functioning and individual career success. In fact, a comprehensive meta-analysis has demonstrated that OCB has a positive impact on productivity, reduced costs, customer satisfaction, 
emplovee retention, employee performance, and reward allocation decisions (Podsakoff, Whiting, Podsakoff, \& Blume, 2009). This strong body of research supports the proposition that how members of the workplace treat one another has a pervasive impact on a variety of positive outcomes.

\subsection{The Present Study}

Notwithstanding the validity of previous research and the insights that have been gleaned, additional research on interviewing etiquette is warranted. In one respect, research is needed to determine what constitutes proper interviewing etiquette today as societal and workplace norms evolve. In line with the increasing popularity and prevalence of tattoos (Osland \& Clinch, 2014), it may be more acceptable to allow them to be visible in professional environments. Furthermore, given the increased trend toward informality and more casual workplaces (Morgan, 2014), it could be more permissible to address recruiters by their first names in lieu of formal titles and last names. On a health front, as most of today's workplaces are smoke-free, coupled with the general trend toward non-smoking among U.S. adults (Centers for Disease Control and Prevention, n.d.), candidates who smell of smoke during an interview may be at a significant disadvantage. As another example, a handwritten thank you note may now by an anachronism with the proliferation of electronic communication. As these examples suggest, interviewing etiquette is likely evolving. An evolutionary process is gradual, and it is important to determine how far along the interviewing etiquette evolutionary spectrum we have moved. While interviewing etiquette will always evolve to reflect changing times, there is value to be gained from obtaining a snapshot of the present state of etiquette affairs.

Table 1. Interviewing etiquette practices

\begin{tabular}{ll}
\hline & \\
1. & $\quad$ Being on time for the interview \\
2. & Addressing interviewers by their formal titles \\
3. & Prepared with extra copies of resume \\
4. & Exchanging business cards \\
5. & Exhibiting a neat and professional appearance \\
6. & Not smelling of cigarette smoke \\
7. & Not wearing too much perfume or cologne \\
8. & Refraining from exhibiting tattoos \\
9. & Carrying a briefcase or portfolio \\
10. & Shaking hands properly \\
11. & Not being too aggressive \\
12. & Keeping cell phone out-of-site and silent \\
13. & Displaying friendly non-verbal behaviors \\
14. & Not using slang \\
15. & Demonstrating good posture \\
16. & Not speaking negatively about employers \\
17. & Displaying eye contact \\
18. & Thanking you at the conclusion of the interview \\
19. & Sending an email thank you note \\
20. & Sending a handwritten thank you note \\
&
\end{tabular}

To serve as the foundation for determining what practices are most important in the context of today's employment interview, the research team for the present study developed a pool of 20 interviewing etiquette practices. Following that the existing body of interviewing etiquette research is fairly small and that previous research has examined a relatively narrow set of practices in isolation, it was necessary to develop a more comprehensive set of practices for this study. The pool of interviewing etiquette practices is presented in Table 1. Some items relate to traditional etiquette practices such as being on time for an interview, shaking hands properly, addressing interviewers by their formal titles 
(e.g., Mr. or Mrs.), and sending handwritten thank you notes (Post, Post, Post, \& Post Senning, 2014). Other items relate to emerging trends and issues, such as cell phone etiquette, sending email thank you notes, and tattoos. Additional items relate to more general interviewer-recruiter interactions, such as not being too aggressive and displaying proper eye contact. The pool of items is not meant to represent an exhaustive list of interviewing etiquette practices. At the time, it is believed they represent sufficient breadth to capture polite behaviors that individuals should consider following during job interviews.

The first issue to be investigated relates to the value recruiters place on different interviewing etiquette practices. Answering this question is important to help students determine what is most important in interviewee-recruiter interactions. A host of interviewing etiquette practices are potentially at one's disposal, and determining what recruiters value most and least will help students better navigate the interviewing etiquette landscape. Furthermore, based on the discussion above, we seek to determine the extent to which recruiters continue to value traditional interviewing etiquette or are adapting with the times by embracing or accepting greater informality among interviewees.

Question 1: To what extent do recruiters value different interviewing etiquette practices?

The second issued to be examined is the extent to which recruiters are in agreement in the value they place on interviewing etiquette practices. Answering this question is important to determine where there are near universal practices and where interviewing etiquette is more in the eye of the beholder. It is likely that recruiters are in relatively high agreement over etiquette governing recruiter-interviewee interpersonal interactions (e.g., maintaining eye contact and not being too aggressive). However, what is more uncertain is the extent to which recruiters agree over more the traditional practices and emerging trends and issues. For example, is there agreement over the importance (or not) of sending a handwritten thank-you note, using formal titles with recruiters, carrying a briefcase or portfolio, keeping one's cell phone out of sight, and refraining from exhibiting tattoos? High disagreement among recruiters for a specific interviewing practice will signal that proper etiquette is largely context dependent. However, high agreement, coupled with a high importance rating, would signal a best practice.

Question 2: For which interviewing etiquette practices are recruiters in general agreement in their importance, and for which practices is there greater variability?

The third research question focuses on whether recruiters in different industry segments value interviewing etiquette differently. Specifically, for this study we focus on three industry segments: 1) business; 2) education and social services; and 3) science and technology. Consistent with national recruiting trends in higher education (National Association of Colleges and Employers, 2017), these segments reflect the companies and organizations that were most active in recruiting students on the campus where this research was conducted. The three industry segments fit well with three of the six career clusters in John Holland's (1992) theory of vocational personalities and work environments: enterprising (business), social (education and social services), and investigative (science and technology). The three industry segments also map onto the North American Industry Classification System's (NAICS) industry classifications, with the exception of one (i.e., arts, entertainment, and recreation) (United States Census Bureau, 2017). On the whole, the industry segments are distinctive and reasonably comprehensive and inclusive. Therefore, we propose the following research question.

Question 3: To what extent do recruiters value interviewing etiquette practices differently across industry segments?

\section{Method}

The sample of recruiters for this study includes 290 individuals from different organizations who are involved in hiring college students for internships and post-graduation employment. These recruiters represent a sample of recruiters who actively hire students through the central career services center at a Northeastern university, comprising approximately $28 \%$ of active on-campus recruiters through this career center. Through an online survey, the recruiters were asked to rate the importance of the 20 interviewing etiquette practices in Table 1. Specifically, the participants were asked to indicate how important is it for college job seekers to adhere to the practice, using a 5-point scale with anchors ranging from 1) not at all important to 5) extremely important. The average age of the recruiters was 39. 26 years old $(s d=11.10)$. Sixty-four percent of the recruiters were female, and they were predominantly Caucasian (87\%). On average, they had been employed with their current employers for 8.44 years ( $s d$ 
$=8.13)$ and possessed 10.46 years of recruiting experience $(s d=8.20)$. One hundred, six of the recruiters were from business, 70 from education and social services, and 114 from science and technology.

\section{$3 \quad$ Results}

Table 2 presents the mean interviewing etiquette ratings for the overall sample and for the recruiters by industry segment. Table 3 provides the interrater agreement indices for the overall sample and by industry segment. The interrater agreement indices $\left(r_{\mathrm{WG}}\right)$ reflect the extent to which the recruiters themselves were in consensuses with their ratings for each of the interviewing etiquette practices (James, Demaree, \& Wolf, 1984). These indices have the potential to range from 0 (no agreement) to 1 (perfect agreement). The following guidelines are useful for the interpretation of interrater agreement: .00 to .30 $=$ lack of agreement; .31 to $.50=$ weak agreement; .51 to $.70=$ moderate agreement; .71 to $.90=$ strong agreement; and .91 to $1.00=$ very strong agreement (LeBreton \& Senter, 2008). In turn, Table 4 provides post hoc comparisons of the etiquette ratings across the industry segments for the practices where significant differences were demonstrated. Specifically, Tukey's post hoc comparisons were conducted, where all possible pairwise differences of means simultaneously are considered.

Table 2. Mean etiquette ratings overall and by industry segment

\begin{tabular}{|c|c|c|c|c|c|c|c|c|c|}
\hline & \multicolumn{2}{|c|}{ Overall } & \multicolumn{2}{|c|}{ Business } & \multicolumn{2}{|c|}{$\begin{array}{l}\text { Education } \\
\text { \& Social } \\
\text { Services }\end{array}$} & \multicolumn{3}{|c|}{$\begin{array}{l}\text { Science \& } \\
\text { Technology }\end{array}$} \\
\hline & $M$ & $S D$ & $M$ & $S D$ & $M$ & $S D$ & $M$ & $S D$ & $F$ \\
\hline 1. Being on time for the interview & 4.85 & .37 & 4.91 & .29 & 4.77 & .46 & 4.84 & .37 & 2.85 \\
\hline 2. Addressing interviewers by formal titles & 2.26 & 1.23 & 2.09 & 1.22 & 2.58 & 1.29 & 2.22 & 1.17 & $3.43^{*}$ \\
\hline 3. Prepared with extra copies of resume & 3.04 & 1.17 & 3.19 & 1.15 & 2.99 & 1.22 & 2.94 & 1.15 & 1.37 \\
\hline 4. Exchanging business cards & 1.74 & .94 & 1.92 & 1.11 & 1.70 & .81 & 1.60 & .82 & $3.49^{*}$ \\
\hline 5. Exhibiting a neat and professional appearance & 4.66 & .61 & 4.83 & .38 & 4.57 & .55 & 4.56 & .77 & $6.64^{* *}$ \\
\hline 6. Not smelling of cigarette smoke & 3.99 & 1.12 & 4.26 & .97 & 3.86 & 1.12 & 3.82 & 1.20 & $5.22^{*}$ \\
\hline 7. Not wearing too much perfume or cologne & 3.51 & 1.14 & 3.77 & 1.04 & 3.26 & 1.15 & 3.43 & 1.19 & $4.96^{*}$ \\
\hline 8. Refraining from exhibiting tattoos & 2.89 & 1.25 & 3.22 & 1.25 & 2.77 & 1.21 & 2.67 & 1.22 & $5.98^{* *}$ \\
\hline 9. Carrying a briefcase or portfolio & 3.72 & 1.01 & 3.93 & 1.03 & 3.43 & 1.03 & 3.70 & .93 & $5.52^{* *}$ \\
\hline 10. Shaking hands properly & 4.68 & .50 & 4.63 & .54 & 4.70 & .49 & 4.72 & .47 & .88 \\
\hline 11. Not being too aggressive & 4.60 & .71 & 4.61 & .74 & 4.64 & .64 & 4.55 & .73 & .39 \\
\hline 12. Keeping cell phone out-of-site and silent & 4.54 & .67 & 4.71 & .48 & 4.50 & .63 & 4.41 & .80 & $5.77^{* *}$ \\
\hline 13. Displaying friendly non-verbal behaviors & 3.76 & .94 & 3.93 & .82 & 3.71 & .95 & 3.62 & 1.01 & $3.19^{*}$ \\
\hline 14. Not using slang & 3.09 & 1.28 & 3.49 & 1.22 & 2.84 & 1.22 & 2.88 & 1.28 & $8.51^{* *}$ \\
\hline 15. Demonstrating good posture & 3.51 & .93 & 3.87 & .84 & 3.27 & .88 & 3.33 & .95 & $13.21^{* *}$ \\
\hline 16. Not speaking negatively about employers & 3.96 & .93 & 4.07 & .80 & 4.00 & 1.04 & 3.83 & .98 & 1.81 \\
\hline 17. Displaying eye contact & 4.19 & .71 & 4.28 & .70 & 4.07 & .80 & 4.18 & .66 & 1.88 \\
\hline $\begin{array}{l}\text { 18. Thanking you at the conclusion of the } \\
\text { interview }\end{array}$ & 4.26 & .81 & 4.47 & .62 & 3.99 & .91 & 4.24 & .85 & $8.12^{* *}$ \\
\hline 19. Sending an email thank you note & 3.41 & 1.15 & 3.59 & 1.15 & 3.14 & 1.12 & 3.39 & 1.14 & $3.33^{*}$ \\
\hline 20. Sending a handwritten thank you note & 2.42 & 1.25 & 2.55 & 1.30 & 2.44 & 1.26 & 2.29 & 1.20 & 1.19 \\
\hline
\end{tabular}

Overall $n=290$; Business $n=106$; Education \& Social Services $n=70$; Science \& Technology $n=114 ;{ }^{*} p<.05$, $* * p<.01$

The first research question sought to answer how much recruiters value the different interviewing etiquette practices. Of the 20 practices, seven items received ratings between 4.00 (very important) and 5.00 (extremely important). Only four practices were rated below 3.00 (somewhat important). Among the highest rated items were being on time for the interview, shaking hands properly, and exhibiting a neat, organized, and professional appearance. Among the lowest rated items were sending a handwritten thank you note, addressing interviewers by their formal titles, and exchanging business cards. 
Table 3. Etiquette rating agreement indices overall and by industry segment

\begin{tabular}{|c|c|c|c|c|}
\hline & Overall & Business & $\begin{array}{l}\text { Education \& } \\
\text { Social Services }\end{array}$ & $\begin{array}{l}\text { Science \& } \\
\text { Technology }\end{array}$ \\
\hline 1. Being on time for the interview & .93 & .96 & .90 & .93 \\
\hline 2. Addressing interviewers by their formal titles & .25 & .25 & .17 & .32 \\
\hline 3. Prepared with extra copies of resume & .32 & .34 & .25 & .34 \\
\hline 4. Exchanging business cards & .56 & .38 & .67 & .67 \\
\hline 5. Exhibiting a neat and professional appearance & .82 & .93 & .85 & .71 \\
\hline 6. Not smelling of cigarette smoke & .38 & .53 & .37 & .28 \\
\hline 7. Not wearing too much perfume or cologne & .35 & .46 & .34 & .29 \\
\hline 8. Refraining from exhibiting tattoos & .22 & .22 & .27 & .26 \\
\hline 9. Carrying a briefcase or portfolio & .49 & .47 & .47 & .57 \\
\hline 10. Shaking hands properly & .87 & .85 & .88 & .89 \\
\hline 11. Not being too aggressive & .75 & .73 & .80 & .73 \\
\hline 12. Keeping cell phone out-of-site and silent & .78 & .89 & .80 & .68 \\
\hline 13. Displaying friendly non-verbal behaviors & .56 & .66 & .55 & .49 \\
\hline 14. Not using slang & .18 & .26 & .25 & .18 \\
\hline 15. Demonstrating good posture & .57 & .65 & .61 & .55 \\
\hline 16. Not speaking negatively about employers & .57 & .68 & .46 & .52 \\
\hline 17. Displaying eye contact & .75 & .76 & .68 & .78 \\
\hline 18. Thanking you at the conclusion of the interview & .68 & .81 & .59 & .64 \\
\hline 19. Sending an email thank you note & .34 & .35 & .37 & .35 \\
\hline 20. Sending a handwritten thank you note & .22 & .16 & .21 & .29 \\
\hline
\end{tabular}

Note: Overall $n=290 ;$ Business $n=106$; Education \& Social Services $n=70$, Science \& Technology $n=114$

The second research question sought to answer the extent to which the recruiters were in agreement in the importance they placed on the interviewing etiquette practices. Across all 20 items, the average agreement index was .53 (moderate agreement), with the indices ranging from .18 (lack of agreement) to .93 (very strong agreement). Among the interviewing etiquette practices with the highest agreement indices were: being on time for the interview, shaking hands properly, and exhibiting a neat, organized, and professional appearance. (These three practices also had the highest mean ratings, as noted above.) Among the interviewing etiquette practices with the lowest agreement indices were: not using slang, refraining from exhibiting tattoos, and sending a handwritten thank you note.

The third research question focused on whether there were differences in the interviewing etiquette ratings among the recruiters across the industry segments. The $F$-statistics in Table 2 provide evidence that were significant differences in the interviewing etiquette ratings for 13 of the 20 interviewing etiquette practices. The post hoc comparisons, which indicate where the differences lie illustrate the following trends. In general, the business recruiters placed greater importance on the interviewing etiquette practices than the recruiters in the other two clusters. In one case, however, the recruiters in education and social services had higher ratings than those in business (addressing recruiters by their formal titles).

Follow-up analyses were also performed to help ascertain whether the recruiters' ratings of the interviewing etiquette practices were somewhat dependent on demographic characteristics. Specifically, we sought to determine whether the recruiters' ratings varied based on demographic characteristics. Regarding gender, three significant differences were found. Females placed greater importance on not being too aggressive $(d=.19, p<.05)$ and not speaking negatively about employers $(d=.32, p<.05)$. However, men rated the importance of not using slang higher than females $(d=.34, p<.05)$. With respect to ethnicity, Caucasian recruiters rated exchanging business cards lower than other ethnicities $(d$ $=.51, p<.01)$. Seven significant correlations were found between age and the interviewing etiquette ratings: addressing interviewers by their formal titles $(r=.15, \mathrm{p}<.01)$; exchanging business cards $(r=$ $-.13, p<.05)$; not wearing too much perfume or cologne $(r=.22, p<.01)$; not using slang $(r=.14, p$ 
$<.05)$; demonstrating good posture $(r=.12, p<.05)$; displaying eye contact $(r=.10, p<.05)$; and, sending a handwritten thank you note $(r=.15, p<.01)$.

Table 4. Post hoc comparisons of etiquette ratings across industry segments

\begin{tabular}{llll}
\hline & $\begin{array}{l}\text { Business - } \\
\text { Education \& }\end{array}$ & $\begin{array}{l}\text { Business - } \\
\text { Science \& }\end{array}$ & $\begin{array}{l}\text { Education \& Social } \\
\text { Services - Science } \\
\text { \& Technology }\end{array}$ \\
\hline Addressing interviewers by formal titles & $-.49^{*}$ & -.12 & .36 \\
Exchanging business cards & .23 & $.33^{*}$ & .10 \\
Exhibiting a neat and professional appearance & $.26^{*}$ & $.27^{*}$ & .01 \\
Not smelling of cigarette smoke & $.41^{*}$ & $.45^{*}$ & .04 \\
Not wearing too much perfume or cologne & $.52^{*}$ & .34 & -.17 \\
Refraining from exhibiting tattoos & $.45^{*}$ & $.55^{*}$ & .10 \\
Carrying a briefcase or portfolio & $.51^{*}$ & .23 & -.27 \\
Keeping cell phone out-of-site and silent & .21 & $.30^{*}$ & .09 \\
Displaying friendly non-verbal behaviors & .22 & $.31^{*}$ & .09 \\
Not using slang & $.65^{*}$ & $.61^{*}$ & -.03 \\
Demonstrating good posture & $.60^{*}$ & $.54^{*}$ & -.06 \\
Thanking you at the conclusion of the interview & $.49^{*}$ & .23 & -.25 \\
Sending an email thank you note & $.45^{*}$ & .20 & -.25 \\
\hline
\end{tabular}

Note: Overall $\mathrm{n}=290 ;$ Business $\mathrm{n}=106$; Education \& Social Services $\mathrm{n}=70$, Science \& Technology $\mathrm{n}=114 ;{ }^{*} \mathrm{p}$ $<.05$

\section{Discussion}

The results from this study offer a valuable snapshot of today's interviewing etiquette landscape. In many respects, much of what is considered traditional interviewing etiquette is still valued among recruiters, such as shaking hands properly and thanking the recruiters at the conclusion of the interview. However, some traditional interviewing etiquette practices were not necessarily valued by recruiters, namely taking notes during the interview and addressing recruiters by formal titles. The recruiters were not always in agreement in the value the placed on the interviewing etiquette practices, which highlights that interviewing etiquette is somewhat context dependent. One size does not necessarily fit all. Ultimately, the findings from this study will help guide students' behavior and stimulate further discussion and research on the role of etiquette in the interviewing process.

Several of the findings are worth highlighting. The average recruiter rating for refraining from exhibiting tattoos was slightly less than 3.00 (somewhat important), suggesting that recruiters are on the fence regarding tattoos and that displaying a tattoo is not necessarily an etiquette breach. However, keeping one's cell phone out-of-sight and silent was among the most highly rated items. Since cell phone etiquette breaches are commonplace (Forgays, Hyman, \& Schreiber, 2014), students must be aware of proper etiquette during the employee selection process. Interestingly, exchanging business cards and sending a handwritten thank you note were not rated highly. On the face of it, one could conclude that these forms of communication are unnecessary. At the time, they could serve to differentiate a job candidate from others and provide competitive advantage. While sending a handwritten thank you note was not rated highly, sending an email thank you note was rated more highly. As such, students may seek to express gratitude and appreciation though this means.

The recruiters' agreement indices provide further insight for interviewing etiquette in practice. For approximately half of the interviewing etiquette practices, the recruiters were in moderate to very strong agreement in their ratings. All but one of these etiquette practices were also rated 3.50 or higher, suggesting that they represent roughly universal interviewing etiquette best practices. Three items with relatively high mean recruiter ratings but low agreement indices were: not smelling of cigarette smoke, carrying a briefcase or portfolio, and not wearing too much perfume or cologne. These relatively high importance scores, coupled with relatively low agreement, signals that adherence to these principles 
matters for many, but opinions vary widely on these matters. From a practical perspective, students should likely err on the side of caution. Adhering to the practices would most likely never hurt one's success in the selection process, but failure do so might have a significant negative impact.

Even though interviewing etiquette is important irrespective of job context, our findings highlight that etiquette may be even more important for students interviewing for jobs in traditional business settings. For about half of the etiquette practices, the business recruiters placed a greater importance on them than did the other recruiters. Among the practices that the business recruiters valued more include: sending an email thank you note, carrying a briefcase or portfolio, and not smelling of cigarette smoke. Accordingly, these findings suggest that students being considered for positions in business must be even more polished and cognizant of the finer points of interviewing etiquette.

Our follow-up analyses also highlight that demographic characteristics influenced the importance placed on some of the interviewing etiquette practices. For example, older recruiters placed greater importance on being addressed by formal titles, not using too much perfume or cologne, and sending a handwritten thank you note. It can be concluded that older recruiters have a slight preference for greater formality, and students should avoid being overly casual. Turning to gender, it was noteworthy that female recruiters placed a greater emphasis on not being too aggressive and not speaking negatively about employers. These findings are consistent with findings that females tend to be more agreeable than men (Burton, Hafetz, \& Henninger, 2007), or that they conform in their thoughts or actions to social gender roles (Eagly, 1987). Another interesting finding was that non-Caucasian recruiters displayed a greater preference for exchanging business cards. Although statistically significant, the effect sizes between the demographic characteristics and the recruiters' interviewing etiquette ratings were only modest. We do not intend to overly generalize, but hope to provide some nuance as to how one might need to adapt one's approach to interviewing etiquette.

Some students may not necessarily be well versed in the principles of proper interviewing etiquette, and advisors are encouraged to have such discussions with students as they embark on their job search endeavors. The results from this study can serve as a starting point for such a dialogue. In addition to focusing on the relative importance of the 20 interviewing etiquette practices, three general principles may be useful for advisors in their interactions with students. One, interviewing etiquette still matters to recruiters. While qualifications and interview answer quality are undoubtedly important, advisors should emphasize that interviewing etiquette may serve as a point of differentiation. Second, it may be best to err on the side of formality. Being too informal might inhibit success in the job interview, as recruiters might infer a lack of work ethic or courtesy when job seekers fail to "mind their manners." Three, it is important to consider the culture of the organizations for which students are seeking employment. While the present study has offered some general interviewing etiquette guidelines, students should match their interviewing etiquette and style to match the brand of companies and their values.

The findings from this study should be interpreted in the context of its limitations. Our samples of recruiters were only drawn from one large Northeastern university. Interviewing etiquette norms may be somewhat company specific, and further research should examine the extent to which the findings generalize or differ with additional samples and industry segments. Regarding background, the great majority of the recruiters were Caucasian and American. As such, the findings should be viewed in this cultural lens.

To extend the findings from this study, several opportunities of future research are worth pursuing in addition to those presented above. One valuable area of inquiry is examining the extent to which adherence to interviewing etiquette results in favorable job search outcomes. It is largely assumed that interviewing etiquette matters, but research is warranted to validate how interviewing etiquette relates to outcomes including number of job offers and starting salaries for successful job candidates. Along the same lines, research should examine how interviewing etiquette influences job search outcomes relative to candidates' experiences, credentials, and other impression management strategies, such as selfpromotion and ingratiation strategies (Kacmar, Delery, \& Ferris, 1992; Stevens \& Kristof, 1995). Future research should also assess what helps translate knowledge into action; that is, what motivates students to engage in proper interviewing etiquette, and what obstacles might inhibit doing so? For example, research could examine how individual differences, such as cognitive ability and personality, relate to adherence to interviewing etiquette. It may be that those who are higher in cognitive ability adhere to interviewing etiquette more carefully because there are more apt to know the right thing to do and 
possess a greater ability to adapt interviewing etiquette to the situation at hand. In the context of the Big Five personality dimensions (Barrick \& Mount, 1991; Hurtz \& Donovan, 2000), those higher in conscientiousness, agreeableness, and extraversion could engage in more interviewing etiquette because they are more motivated to so.

In today's dynamic and competitive labor market, college students need to put their best foot forward to obtain the best possible internships and post-graduation employment. Although candidates should focus on demonstrating that they possess the requisite knowledge, skills, and abilities for the position at hand, they should also remember to exhibit courtesy. Doing so will likely give them a competitive edge by differentiating oneself on an interpersonal basis. A host of interviewing etiquette tactics are at one's disposal, and it may be a difficult to determine which strategies matter most. It is our hope that the results from this study will provide job hunters a more nuanced picture regarding the importance of different interviewing etiquette practices and how one should adapt etiquette based on the situation at hand.

\section{References}

1. Barrick, M.R., \& Mount, M.K. (1991). The big five personality dimensions and job performance: A meta-analysis. Personnel Psychology, 44, 1-26.

2. Burton, L.A., Hafetz, J., \& Henninger, D. (2007). Gender differences in relational and physical aggression. Social Behavior and Personality: An International Journal, 35, 41-50.

3. Centers for Disease Control and Prevention. (n.d.). Retrieved February 19, 2017, from https://www.cdc.gov/ tobacco/data_statistics/tables/trends/cig_smoking/.

4. Eagan, K., Stolzenberg, E.B., Bates, A.K., Aragon, M.C., Suchard, M R., \& Rios-Aguilar, C. (2015). The American freshman: National norms fall 2015. Los Angeles, CA: Higher Education Research Institute, UCLA.

5. Eagly, A.H. (1987). Sex differences in social behavior: A social-role interpretation. Hillsdale, NJ: Lawrence Erlbaum Associates, Inc.

6. The Emily Post Institute. (n.d.). Retrieved February 19, 2017, from http://emilypost.com/advice-type/business/.

7. Etiquette. (n.d.). In Oxford Dictionaries, Retrieved February 19, 2017, from https://en.oxforddictionaries.com/ definition/us/etiquette.

8. Forgays, D.K., Hyman, I., \& Schreiber, J. (2014). Texting everywhere for everything: Gender and age differences in cell phone etiquette and use. Computers in Human Behavior, 31, 314-321.

9. Gardner, W.L. (1992). Lessons in organizational dramaturgy: The art of impression management. Organizational Dynamics, 21, 33-46.

10.Holland, J.L. (1992). Making vocational choices: A theory of vocational personalities and work environments. Odessa, FL: Psychological Assessment Resources.

11.Hurtz, G.M., \& Donovan, J.J. (2000). Personality and job performance: The big five revisited. Journal of Applied Psychology, 85, 869-879.

12.James, J.R., Demaree, R.G., \& Wolf, G. (1984). Estimating within-group interrater reliability with and without response bias. Journal of Applied Psychology, 69, 85.

13.Johnson, D., \& Tyler, L. (2013). Modern manners: Tools to take you to the top. New York, NY: Crown Publishing Group.

14.Kacmar, K.M., Delery, J.E., \& Ferris, G.R. (1992). Differential effectiveness of applicant impression management tactics on employment interview decisions. Journal of Applied Social Psychology, 22, 1250-1272.

15.Kristof, A.L. (1996). Person-organization fit: An integrative review of its conceptualizations, measurement, and implications. Personnel Psychology, 49, 1-49.

16.Kristof-Brown, A.L., \& Guay, R.P. (2011). Person-environment fit. In S. Zedeck (Ed.), American Psychological Association handbook of industrial and organizational psychology (vol. 3, pp. 3-50). Washington, DC: American Psychological Association.

17.LeBreton, J.M., \& Senter, J.L. (2007). Answers to 20 questions about interrater reliability and interrater agreement. Organizational Research Methods, 11, 815-852.

18.Lipscomb, T.J., Totten, J.W., Cook, R.A., \& Lesch, W. (2007). Cellular phone etiquette among college students. International Journal of Consumer Studies, 31, 46-56. 
19.Mishra, A., \& Mishra, S. (2015). Attitude of Professionals and Students towards Professional Dress Code, Tattoos and Body Piercing in the Corporate World. International Journal of Innovative Research and Development, 4, 324-331.

20.Morgan, J. (2014). The future of work: Attract new talent, build better leaders, and create a competitive organization. Hoboken, NJ: Wiley.

21.National Association of Colleges and Employers. (2017). Job outlook 2017. Bethlehem, PA.

22. Organ, D.W. (1988). Organizational citizenship behavior: The good soldier syndrome. Lexington, MA: Lexington Books.

23. Osland, A., \& Clinch, N. (2014). Tattoos in the workplace. Journal of Critical Incidents, 7, 75-77.

24.Podsakoff, N.P., Whiting, S.W., Podsakoff, P.M., \& Blume, B.D. (2009). Individual-and organizational-level consequences of organizational citizenship behaviors: A meta-analysis. Journal of Applied Psychology, 94, 122141.

25.Post, P., Post, A., Post, L., \& Post Senning, D. (2014). The etiquette advantage in business, third edition: personal skills for professional success. New York, NY: HarperCollins.

26.Ryan, R. (2016). 60 seconds and you're hired. New York, NY: Penguin Books.

27.Stevens, C.K., \& Kristof, A.L. (1995). Making the right impression: A field study of applicant impression management during job interviews. Journal of Applied psychology, 80, 587-606.

28.Swanger, N. (2006). Visible body modification (VBM): Evidence from human resource managers and recruiters and the effects on employment. International Journal of Hospitality Management, 25, 154-158.

29.Timming, A.R. (2015). Visible tattoos in the service sector: A new challenge to recruitment and selection. Work, Employment and Society, 29, 60-78.

30.United States Census Bureau. (2017). North American industry classification system. Retrieved from https://www.census.gov/eos/www/naics/2017NAICS/2017_NAICS_Manual.pdf

31.Yate, M. (2012). Knock 'em dead job interview. Avon, MA: Adams Media. 